Research Paper

\title{
Tumor deposit is an independent prognostic indicator in patients who underwent radical resection for colorectal
}

\section{cancer}

\author{
Shiva Basnet1,3,5, Qi-feng Lou1, Nan Liu'1, Ramesh Rana7, Abilasha Shah", Mamata Khadka6, Hemanshu \\ Warrier ${ }^{9}$, Shushil Sigdel ${ }^{4}$, Sunil Dhakal ${ }^{4}$, Anita Devkota ${ }^{4}$, Roshan Mishra ${ }^{4}$, Ganga Sapkota ${ }^{4}$, Liang Zheng ${ }^{2}{ }^{\bowtie}$, \\ Hai-yan $\mathrm{Ge}^{1}$ \\ 1. Department of Gastrointestinal Surgery, Shanghai East Hospital, Tongji University School of Medicine, Shanghai, China \\ 2. Research Centre for Translational Medicine, Key Laboratory of Arrhythmias, Ministry of Education, Shanghai East Hospital, Tongji University School of Medicine, Shanghai, China \\ Dulegaunda Polyclinic and Research Centre, Gandaki Province, Nepal \\ B.P Koirala Memorial Cancer Hospital Bharatpur Nepal \\ Metro city Hospital and Research Centre Gandaki Province Nepal \\ University of Maryland College Park, School of Public Health, USA \\ Department of Internal Medicine, Gautam Buddha Community Heart Hospital Butwal Nepal. \\ National Center for Rheumatic Diseases, Ratopul Kathmandu Nepal. \\ Max Hospital, Emergency Department, New Delhi Gurgaon India
}

$\square$ Corresponding author: Hai-yan Ge, Email: ghy1333@easthospital.cn; Liang Zheng, Email: zhengliang@tongji.edu.cn; Department of Gastrointestinal Surgery, Shanghai East Hospital, Tongji University School of Medicine, Pudong New District, No. 150, Jimo Road, Shanghai, 200120, China. Tel: +86 2138804518 Fax: +86 2158798999

(c) Ivyspring International Publisher. This is an open access article distributed under the terms of the Creative Commons Attribution (CC BY-NC) license (https:// creativecommons.org/licenses/by-nc/4.0/). See http://ivyspring.com/terms for full terms and conditions.

Received: 2018.05.25; Accepted: 2018.08.28; Published: 2018.10.10

\begin{abstract}
Background: Tumor deposits are one of the promising factors among the different edition of Tumor, Node, Metastasis classification. Despite improvement in the treatment of various types of metastatic disease the source and prognostic significance of tumor deposits in staging has not been deliberating the agreeable opinion. We investigated the possibility of tumor deposit as independent prognostic factor and evaluating its prognostic value in colorectal carcinoma patients.

Methods: Author studied 313 colorectal cancer patients clinocopathological data and outcome who underwent radical resection. Data between 2011-2015 were retrospectively collected from Shanghai East Hospital, affiliated with Tongji University data information centre. The analysis was used to calculate 2 years disease free survival(DFS) and relation of tumor deposit with number of lymph node positive. Cox-regression analysis was performed to assess the prognostic factor.

Results: Out of 313 colorectal patients included in the study, tumor deposits were detected in $17 \%$. Tumor deposits (TDs) are relevantly associated with significant poor outcomes. The tumor deposit were significantly correlated with T-stage $(P=<0.001)$, $N$-stage $(P=<0.001)$, $P L N C(P=<0.001)$, venous invasion $(P=<0.001)$, TNM staging $(P=<0.001)$, $C E A(P=0.021)$ and $C A 19-9(P=0.042)$ of primary tumor. The Kaplan-Meier analysis revealed that disease-free survival of CRC patients with positive tumor deposit were significantly poorer that those with negative tumor deposit cohort $(\mathrm{P}=<0.001)$ And with multivariate analysis in different model, we found that positive tumor deposit were significantly associated with shorter DSF which is totally independent with lymph node status $(P=0.001$ and $P=0.023$ respectively). Subgroup analysis found that of $179 \mathrm{CRC}$ patients with negative lymph node status, the DFS of patients with positive tumor deposit were significantly shorter that those with negative tumor deposit $(\mathrm{P}=, 0.001)$. Of 134patients with positive lymph node status, the DFS of patients shows similar result. $(\mathrm{P}=<0.001)$.

Conclusion: We have shown that TDs are not equal to lymph node metastasis with respect to biology and outcome. Tumor deposits are an independent adverse prognostic factor in CRC patient who have undergone radical resection.
\end{abstract}

Key words: Colorectal cancer, Tumor deposit, Prognosis, Survival, lymph nodes.

\section{Introduction}

Colorectal cancer is one of the most prevalent malignancy in Gastrointestinal tract (GIT) worldwide.
It is the $2^{\text {nd }}$ most common cause of death in western society with an estimated 140,250 new cases and an 
estimated 50,630 deaths for both the sexes in united states[1]. It is the third most common cause of cancer death globally, and both the sexes have an approximately $5 \%$ chance of developing bowel cancer in their lifetime[2]. Colorectal cancer is most frequently diagnosed among adults aged 65 to 74 years; the median age at death from colorectal cancer is 73 years [3]. Generally, persons over age 50 are more vulnerable to develop the disease; however the prevalence is rising in the younger population globally[4]. Colorectal cancer mortality rate are decreasing overall globally despite increase in incidence[5], yet, in some countries, probably due to fewer resources in screening for the disease, incidence rates and mortality are increasing[6]. Good prognosis is observed in colorectal cancer if diagnosed early, and it is likely to respond to effective treatment, resulting in increased survival time, less morbidity, and cost efficiency treatment.

Since $20^{\text {th }}$ century, peri colorectal adipose tissue in colorectal cancer has been recognized as tumor deposits[7]. Tumor deposits are fairly small bits of tumor that are found in the adipose tissue outside the colon or rectum, but are not in lymph nodes. Discussion about tumor deposits regarding nodal staging has created an international debate. The TNM $6^{\text {th }}$ edition states that tumor deposits in pericolic and meso-rectal fat with primary tumor are counted in positive lymph node group, but irregular tumor deposits with a form consistent lymph nodes and venous invasion are placed in the T-category[8]. The American Joint Committee on Cancer Staging Manual $7^{\text {th }}$ Edition(AJCC $7^{\text {th }}$ TNM) and college of American Pathologist cancer protocol has defined pericolic or perirectal fats having discontinuous tumor spread, extravascular spread with venous invasion or totally replaced lymph nodes strongly suggest the tumor deposits[9, 10]. T category lesions(T1 and T2) lacking positive lymph nodes but having tumor deposits has been classified as $\mathrm{pN1c}[9]$. The aim of cancer staging is to deliver the evidence and guidelines for making accurate clinical decisions in treatment of cancer patients and giving prognosis opinions. Several researchers have shown that the presence of TD is associated with poor disease-free survival (DFS) and overall survival (OS)[11].

\section{Materials and methods}

\section{Patients Characteristics}

In the present study we retrospectively analyzed the medical records of all newly diagnosed CRC patients between February 2011 to June 2015 in Shanghai East Hospital, affiliated with Tongji University. The diagnosis of CRC was confirmed according to the histological evidence contained in the $7^{\text {th }}$ edition of the TNM/AJCC classification. The presence of tumor deposits was reviewed for all patients along with other pathological factors. Irregular deposits, either microscopic or macroscopic, spotted in pericolic or perirectal adipose tissue in the bowel specimen without lymphocytic entireties or in the mesocolic/mesorectal specimen with no association of organized lymphoid tissue and without thick bundles of collagen fibers were counted as tumor deposits (TNM6). Similarly, cancer deposits adjacent to metastatic lymph nodes presumed to be in the process of lymph node metastasis but limited in lymphatic or venous structure or having tumor foci less than $5 \mathrm{~mm}$ from the predominant edge were not supposed to be tumor deposits[12-14]. Every patient slide was reviewed, and their baseline information, along with age, sex, tumor grade, histological type, invasion depth, number of lymph nodes excised, number of positive lymph nodes, vascular invasion and perineural invasion were collected for final analysis.

\section{Patients follow-up}

Patients were followed up regularly according to NCCN guidelines. Physical examination, and serum tumor markers, including CEA, were achieved every 3 to 6 months. Colonoscopy was performed at the $1^{\text {st }}$ and $2^{\text {nd }}$ year after surgery. CT-scanchest/abdomen/pelvis surveillance was performed annually. As this study described the prognosis of patients with CRC, we determined DFS events and performed the analysis. Disease-free survival (DFS) was defined as the time from treatment to first recurrence, death of any cause or until the date of last follow up.

\section{Statistical analysis}

Statistical evaluation was conducted with SPSS 23.0 (SPSS, Chicago, IL), $\chi^{2}$ test and multivariate logistic regression analysis were used to analyze the relationship between clinicopathological parameters and tumor deposits. The presence of TDs (using various definitions in the literature) and their relation to survival was carried out using Kaplan-Meier curves, and the difference of variables were compared using log-rank tests. Univariate analysis was used to figure out the association between various prognostic predictors and DFS. The prognostic factors with $\mathrm{P}<0.10$ in univariate analysis were further analyzed through multivariate analysis by using Cox proportional hazard model using stepwise selection to identify independent predictors. All confidence intervals (CIs) were stated at the 95\%confidence level. Two-sided P-values were calculated, and for 
independent prognostic predictors associated with DFS, $\mathrm{P}<0.05$ was considered statistically significant.

\section{Results}

From February 2011 to June 2015, we identified 313 CRC patients who underwent radical resection. Detailed clinicopathological data of 313 CRC patients is shown in Table 1 . The majority of patients were male $(61 \%)$ and more than 65 years old $(63.3 \%)$. Most patients presented with primary colon cancer (55.9\%). Positive tumor deposits were detected in $16.93 \%$ (53/313) of total patients. Various clinicopathologic characteristics were assessed and compared according to tumor deposit status. We found that T-stage $(\mathrm{P}=0.001), \quad \mathrm{N}$-stage $(\mathrm{P}=0.001), \quad \mathrm{TNM}$ staging $(\mathrm{P}=0.001)$, venous invasion $(\mathrm{P}=0.001)$, positive lymph node count $(\mathrm{P}=0.001$, fisher exact test), $\mathrm{CEA}(\mathrm{P}=0.001)$, and $\mathrm{CA19-9}$ $(\mathrm{P}=0.001)$ of primary tumor were significantly corelated with the presence of tumor deposits.

Univariate analysis showed that the preoperative CEA or CA19-9 levels, pT, N, M, PLNC, vascular invasion, tumor deposits and TNM staging were all correlated with DFS (all $\mathrm{P}=0.0001$ ). DFS curve for TDs and PLNC are shown in Figure 1,2, and 3. The univariate and multivariate models for all patients were calculated separately for each variable to avoid potential bias (Table 2,3). As a result, TDs were identified as independent prognostic factors for DFS (HR $[95 \% \mathrm{CI}]=4.296[2.364-7.805] \mathrm{P}$-value $=<0.001$ ) in univariate analysis. Similar results were found in the multivariate Model I-DFS (HR $[95 \% \mathrm{CI}]=4.497[2.448-8.269] \quad \mathrm{P}$-value $=$ $<0.001$ ), Model II- DFS (HR [95\% CI] $=2.819[1.492-5.327] \quad P$-value $=0.001)$, Model III-DFS (HR [95\% CI] =2.194 [1.132-4.225] $\mathrm{P}$-value $=0.020$ ). Overall the P-value for all the analysis in various models (univariate and multivariate) was $<0.05$.

\section{Subgroup survival analysis according to the status of lymph node metastasis and tumor deposits}

In subgroup analysis we focused on the data including lymph nodes positively and negatively associated with positive tumor deposits and negative tumor deposits. We analyzed the survival curve via K-M method for lymph node positive $(\mathrm{n}=134, \mathrm{P}=<0.001$,
Table 1. Baseline clinicopathological characteristics and the status of tumor deposit in CRC patients underwent radical resection.

\begin{tabular}{|c|c|c|c|c|c|c|}
\hline \multirow{2}{*}{ Parameters } & \multicolumn{2}{|c|}{ Patients } & \multicolumn{2}{|c|}{ Tumor Deposit Status } & \multirow{2}{*}{)$^{t / x^{2}}$} & \multirow{2}{*}{$P$-Value } \\
\hline & $\begin{array}{l}\text { No/ } \\
313\end{array}$ & $\% / 100$ & Positive, $n(\%)$ & Negative, $n(\%)$ & & \\
\hline Age (in years) & & & & & & 0.087 \\
\hline$<65$ & 115 & 36.7 & $14(26.4)$ & $101(33.8)$ & & \\
\hline$\geq 65$ & 198 & 63.3 & $39(73.6)$ & $159(61.2)$ & & \\
\hline Sex & & & & & & 0.678 \\
\hline Male & 191 & 61 & $31(58.5)$ & $160(61.5)$ & & \\
\hline Female & 122 & 39 & $22(41.5)$ & $100(38.5)$ & & \\
\hline Tumor Location & & & & & & 0.424 \\
\hline Colon & 175 & 55.9 & $27(50.9)$ & $148(56.9)$ & & \\
\hline Rectum & 112 & 44.1 & $26(49.1)$ & $112(43.1)$ & & \\
\hline T-Stage & & & & & 25.71 & 0.001 \\
\hline $\mathrm{T} 1$ & 17 & 5.4 & $0(0)$ & $17(6)$ & & \\
\hline $\mathrm{T} 2$ & 60 & 19.2 & $3(5.7)$ & $57(21.9)$ & & \\
\hline $\mathrm{T} 3$ & 135 & 43.1 & $17(32.1)$ & $118(45.4)$ & & \\
\hline $\mathrm{T} 4$ & 101 & 32.3 & $33(62.3)$ & $68(26.2)$ & & \\
\hline $\mathrm{N}$-Stage & & & & & 49.85 & 0.001 \\
\hline No & 161 & 51.4 & $4(7.5)$ & $157(60.4)$ & & \\
\hline N1 & 116 & 37.1 & $34(64.2)$ & $82(31.5)$ & & \\
\hline N2 & 36 & 11.5 & $15(28.3)$ & $21(8.1)$ & & \\
\hline M-stage & & & & & & $\begin{array}{l}0.246 \\
\text { (fisherexact) }\end{array}$ \\
\hline M0 & 300 & 95.8 & $49(92.5)$ & 251(96.5) & & \\
\hline M1 & 13 & 4.2 & $4(7.5)$ & $9(3.5)$ & & \\
\hline TNM Staging & & & & & 38.46 & 0.001 \\
\hline I & 53 & 16.9 & $0(0)$ & $53(20.4)$ & & \\
\hline II & 104 & 33.2 & $4(7.5)$ & $100(38.5)$ & & \\
\hline III & 143 & 45.7 & $45(84.9)$ & $98(37.7)$ & & \\
\hline IV & 13 & 4.2 & $4(7.5)$ & $9(3.5)$ & & \\
\hline Differentiation & & & & & & 0.109 \\
\hline Well/moderate(G1+G2) & 234 & 74.8 & $35(66)$ & $119(76.5)$ & & \\
\hline Poor/Unknown(G3+G4) & 79 & 25.2 & $18(34)$ & $61(23.5)$ & & \\
\hline Venous invasion & & & & & & 0.001 \\
\hline Negative & 153 & 48.9 & $14(26.4)$ & $139(53.5)$ & & \\
\hline Positive & 160 & 51.1 & $39(73.6)$ & $121(46.5)$ & & \\
\hline PLNC & & & & & & $\begin{array}{l}0.001 \text { (fisher } \\
\text { exact test) }\end{array}$ \\
\hline$<5$ & 288 & 92.0 & $42(79.2)$ & $246(94.6)$ & & \\
\hline$\geq 5$ & 25 & 8.0 & $11(20.8)$ & $14(5.4)$ & & \\
\hline CEA & & & & & & 0.021 \\
\hline$<5 \mathrm{u} / \mathrm{ml}$ & 169 & 54.0 & $21(39.6)$ & $148(56.9)$ & & \\
\hline$\geq 5$ & 144 & 46.0 & $32(60.4)$ & $112(43.1)$ & & \\
\hline CA19-9 & & & & & & 0.042 \\
\hline$<37 \mathrm{u} / \mathrm{ml}$ & 265 & 84.7 & $40(75.5)$ & $225(86.5)$ & & \\
\hline$\geq 37$ & 48 & 15.3 & $13(24.5)$ & $35(13.5)$ & & \\
\hline
\end{tabular}

Table 2. Univariate analysis of association between clinicopathological factors and disease -free survival in CRC patients underwent radical resection.

\begin{tabular}{lllllll}
\hline Prognostic Factor & B-value & SE & Wald-x Value & P-value & HR & 95\%CI \\
\hline Age & -.076 & .310 & .060 & .806 & .927 & $.505-1.700$ \\
Sex & .302 & .303 & .997 & .318 & 1.356 & $.747-2.449$ \\
Tumor Location & .076 & .304 & .062 & .803 & 1.079 & $.594-1.959$ \\
T -category & .661 & .213 & 9.600 & .002 & 1.937 & $1.272-2.942$ \\
N-Category & 1.093 & .204 & 28.72 & $<.0001$ & 2.983 & $2.000-4.449$ \\
M -category & 1.551 & .440 & 12.43 & $<.0001$ & 4.714 & $1.991-11.161$ \\
TNM & 1.087 & .231 & 22.185 & $<.0001$ & 2.964 & $1.886-4.650$ \\
CEA & .776 & .313 & 5.978 & .014 & 2.152 & $1.164-3.378$ \\
CA-199 & 1.489 & .307 & 23.508 & $<.0001$ & 4.434 & $2.423-8.095$ \\
PLNC & 1.667 & .339 & 24.154 & $<.0001$ & 5.295 & $2.724-10.293$ \\
Vascular Invasion & 1.714 & .412 & 17.276 & $<.0001$ & 5.548 & $2.473-12.447$ \\
Tumor Deposit & 1.458 & .305 & 22.887 & $<.0001$ & 4.296 & $2.364-7.806$ \\
\hline \multicolumn{7}{l}{ Abbreviation: SE, standard error; HR, hazard ratio; CI, confidence interval; PLNC, Positive lymph }
\end{tabular}
node count. 
Fig 2), and the result showed that DFS of patients with positive tumor deposits $(n=31)$ was significantly shorter than that of negative tumor deposits. Similarly, Positive tumor deposits $(n=22)$ in a lymph node- negative scenario delivered the similar results $(\mathrm{n}=179, \mathrm{P}=<0.001$, Fig 3). Furthermore, in positive lymph node count we analyzed the data irrespective to the number of lymph node positives $<5$ and $\leq 5$. The result for positive lymph node count $<5 \quad(n=109$, P-value $=<0.001$, Fig-4) showed that DFS of patients with positive tumor deposit $(n=20)$ were significantly shorter than that of negative tumor deposit group. Likewise, in positive lymph node count $\geq 5$ ( $n=25$, P-value $=<0.001$,Fig-5) group exhibited a similar result.

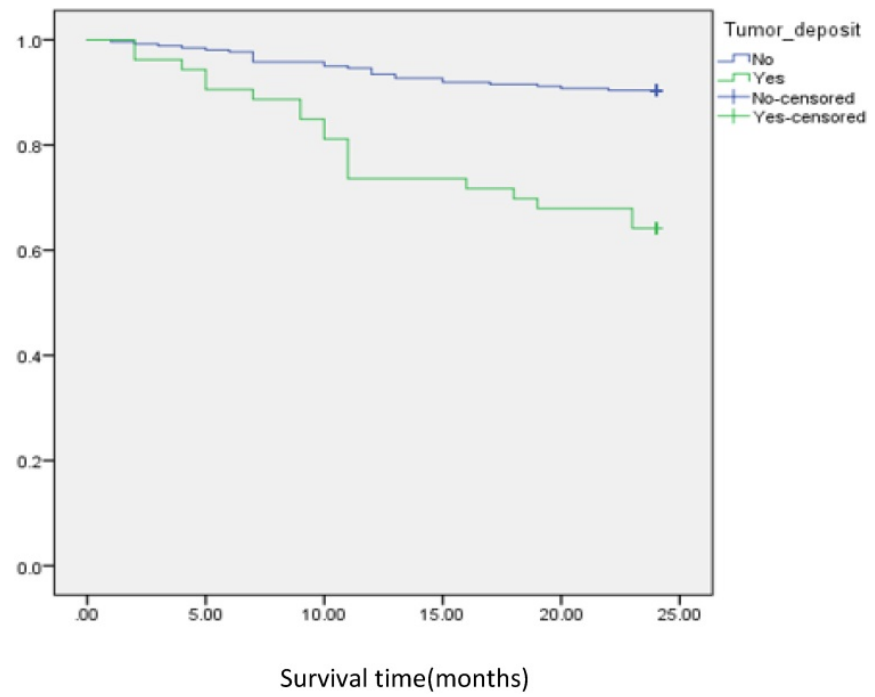

Figure 1. Analysis of disease free survival according to the status of tumor deposit in CRC patients.

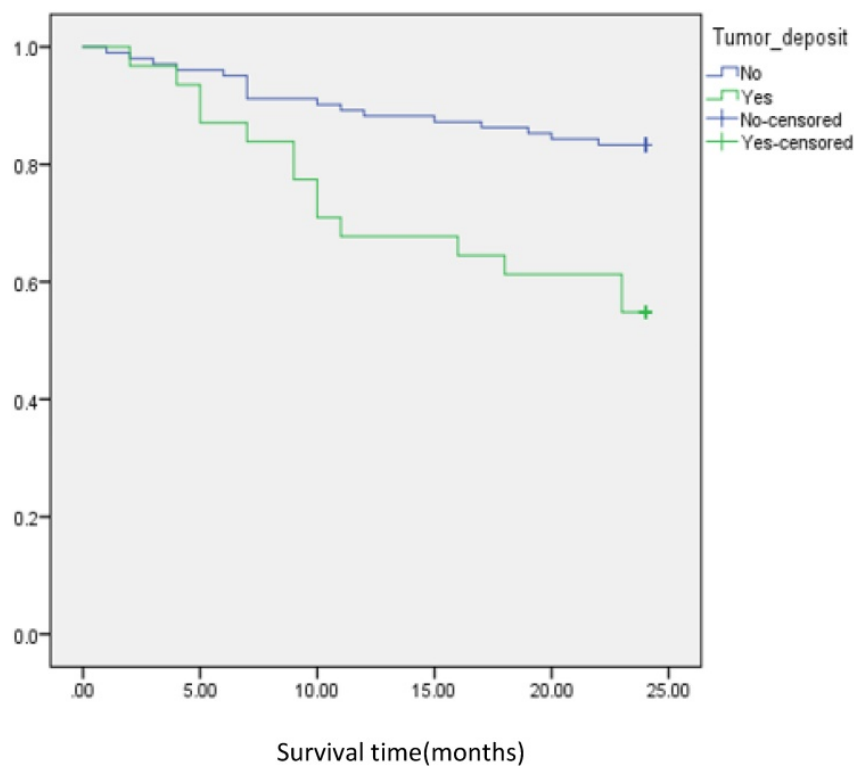

Figure 2. Analysis of disease free survival according to the status of tumor deposit in metastatic CRC patients with positive lymph node.

\section{Discussion}

In the past few decades, there has been considerable improvement in overall survival rate in CRC patients; however, multiple questions remain to be solved regarding histopathological and predictive factors. Despite the presence of TDS in some studies that have demonstrated independent prognostic value, it is not sufficient to clear the confusion.

The existence of PTDs has been termed "vascular tumor dissemination" since 1935; however there was uncertainty with discontinuous adenocarcinoma along with lymph nodes[7]. Based on patient survival data, the 1997 TNM staging system for colorectal cancer put forward the idea of $3 \mathrm{~mm}$ rule regarding positive tumor deposits. A PTD greater than $3 \mathrm{~mm}$ was classified as regional lymph node metastasis, and PTDs equal to or less than $3 \mathrm{~mm}$ were classified as discontinuous T3 adenocarcinomas[15]. This interpretation was replaced in TNM $6^{\text {th }}$ edition which described the number of the nodules. The form and smooth contour of TDs without histological evidence of lymph nodes were reported as LNMs, whereas irregular TDs were defined as venous invasion and T-category[8]. The current TNM/AJCC $7^{\text {th }}$ Edition defines primary carcinomas with tumor deposits in peri-colorectal adipose tissue and lymph drainage sites with no histologic evidence of lymph node residues as possibly indicating discontinuous spread, venous invasion or a totally replaced lymph node.

Table 3. Multivariate analysis of association between clinicopathological factors and disease -free survival in CRC patients underwent radical resection.

\begin{tabular}{lllllll}
\hline Prognostic Factor & \multicolumn{2}{l}{ B-value SE } & $\begin{array}{l}\text { Wald-x } \\
\text { value }\end{array}$ & p-value HR & 95\%CI \\
\hline Model-I & & & & & & \\
Age & -2.90 & .315 & .848 & .357 & .748 & $.403-1.388$ \\
Sex & .285 & .303 & .887 & .346 & 1.330 & $.735-2.408$ \\
Tumor deposit & 1.503 & .310 & 23.478 & $<.0001$ & 4.497 & $2.448-8.262$ \\
Model-II & & & & & & \\
Age & -.291 & .321 & .882 & .365 & .748 & $.339-1.402$ \\
Sex & .281 & .305 & .850 & .357 & 1.324 & $.729-2.407$ \\
Tumor Deposit & 1.036 & .325 & 10.191 & .001 & 2.819 & $1.492-5.327$ \\
CEA & .169 & .344 & .240 & .624 & 1.184 & $.603-2.325$ \\
CA19-9 & 1.042 & .343 & 9.257 & .002 & 2.836 & $1.449-5.551$ \\
Model-III & & & & & & \\
T-category & .168 & .237 & .504 & .478 & 1.183 & $.743-1.884$ \\
N-category & .237 & .472 & .253 & .615 & 1.268 & $.503-3.198$ \\
M-category & .984 & .798 & .1 .520 & .218 & 2.675 & $.560-12.790$ \\
TNM & .127 & .509 & .063 & .802 & 1.136 & $.419-3.083$ \\
Tumor Deposit & .786 & .338 & 5.441 & .020 & 2.194 & $1.132-4.225$ \\
CEA & .394 & .328 & 1.442 & .230 & 1.483 & $.779-2.288$ \\
PLNC & .750 & .574 & 1.706 & .191 & 2.117 & $.687-6.23$ \\
Vascular invasion & 1.194 & .435 & 7.531 & .006 & 3.301 & $1.407-7.746$ \\
\hline Abbreviation: SE, standard error; HR, hazard ratio; CI, confidence interval; PLNC, \\
Positive lymph node count. & & & & & \\
& & & & & &
\end{tabular}




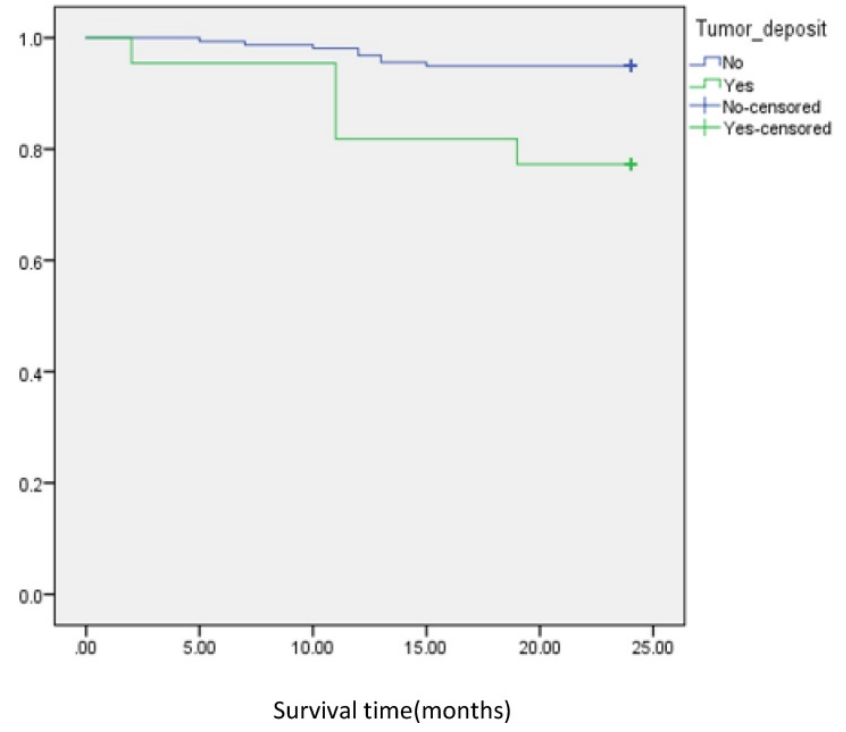

Figure 3. Analysis of disease free survival according to status of tumor deposit in metastatic CRC patients with negative lymph node.

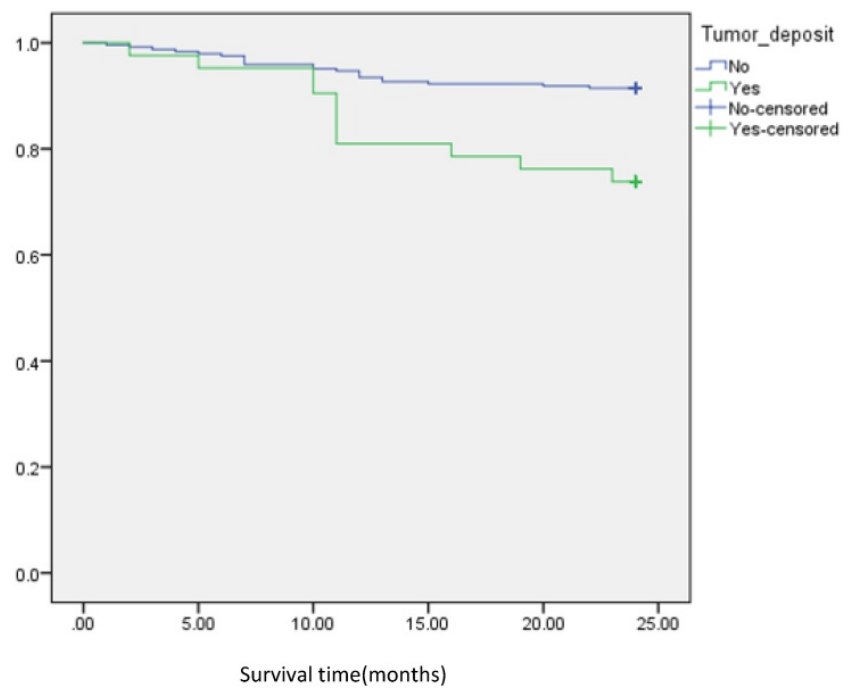

Figure 4. Analysis of disease free survival according to status of tumor deposit in metastatic CRC patients with positive lymph node count $<5$

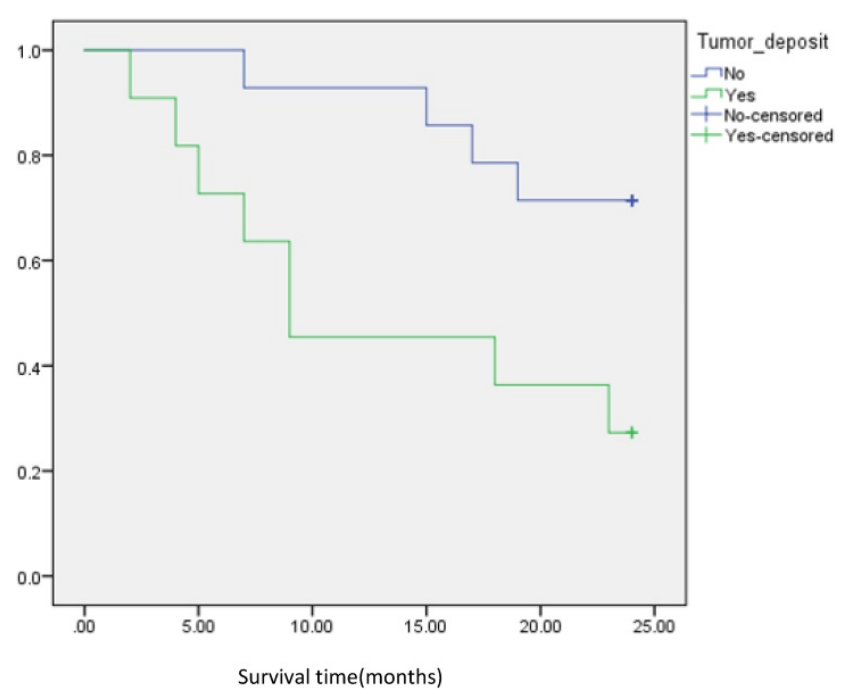

Figure 5. Analysis of disease free survival according to status of tumor deposit in metastatic CRC patients with positive lymph node count $\geq 5$
In such circumstances, the TDs would otherwise be recognized as $\mathrm{T} 1$ or $\mathrm{T} 2$ without changing T-classification, likewise, TDs nodules are included in N1c category stage III $[9,16]$. The modification in definitions of TNM/AJCC staging has created a confusion concerning patients' prognosis and postoperative chemoradiotherapy.

In this study, we investigated the prognostic significance of TDs in Colorectal cancer. Ono C et al. reported that TDs occur from $17 \%$ to $55 \%$ in colon and $6 \%$ to $64 \%$ in CRC[17] Similarly, mayo at el exhibit that TDs is associated with worse 3-years OS in patients of any known and unknown $\mathrm{N}$ categories.[18]. However, Some studies observed diagnostic clarity and prognostic accuracy with positive tumor deposits, regardless of contour classification based on N-type, make the tumor staging system efficient[19]. In contrast, the prognostic information of TDs will be missed if TDs are allocated with nodal category N1c and only TDs in the absence of LNM are considered[20]. Our Data signify that TDs are an independent prognostic factor associated with metastatic diseases, along with vascular invasion and the number of lymph node metastases among CRC patients. This result illustrates that the relationship between TDs accompanying with neural invasion and lymph node metastasis might be an invasive epicenter which appears from lymphatic channels and nerve sheath infiltration as an aggressive tumor cell. In similar articles, Ratto $C$ et al. has described the question about the origin of aggressive tumor cells[21].

Additionally, our univariate analyses of some known prognostic factors, including T-category HR $[95 \% \mathrm{CI}]=1.937[1.272-2.942], \mathrm{N}$-category HR [95\%CI] $=2.983[2.00-4.449]$, vascular invasion $\mathrm{HR}$ [95\% CI] $=5.548[2.473-12.447]$ and PLNC HR $[95 \% \mathrm{CI}]=5.295$ [2.724-10.293] confirmed that these variables deliver independent prognostic characteristics. Similarly, prognostic effect of tumor deposit was evaluated either in univariate or various multivariate models. The following were observed: univariate analysis for tumor deposit HR [95\%CI] =4.296[2.448-8.262], model -I multivariate analysis tumor deposit HR [95\% CI] $=4.497[2.448-8.262]$, model-II multivariate analysis tumor deposit HR [95\% CI] =2.819[1.492-5.327] model -III multivariate analysis tumor deposit HR [95\% CI] $=2.194[1.132-4.225]$. Overall analysis showed that tumor deposits independently carry strong prognostic value. (all P-value <0.05)

This study justifies the validity of positive TDs with a worse outcome for CRC patients. Similar findings from separate studies have demonstrated that TD-positive patients have a tendency toward worse outcomes than TDs negative patients[22]. In 
addition, several research studies have demonstrated the prognostic value of TDS but have not clarified whether TDs should be considered as positive lymph node in CRC[11, 22, 23]. At the same time, some research has focused on considering TDs independently from lymph node metastasis (LNM) because of possible differences in the impact on survival between these two modes of discontinuous spread[24, 25]. Accordingly, there remains confusion whether TDs should be considered as positive lymph node in CRC using the N1a, N1b or N2 category. For any known or unknown $\mathrm{N}$ category, our data showed that TDs are associated with worse 2-years DFS. Mayo et al. has similar speculation regarding $\mathrm{N}$ category and association of TDs with worse survival outcome. TDs may be associated with a risk of all cause death or cancer specific death similar to positive lymph node in all $\mathrm{N}$ categories[18].

Several findings suggest the increasing numbers of PTDs in CRC patients are associated with decreased survival and intra-abdominal metastases[26]. The origin of TDs is diverse, it is accepted that PTD have a component of large vessels, perineural or intravascular adenocarcinoma[26, 27]. Our analyses ascertain that TDS are not LNMs, they should be considered independent prognostic indicators which give a concise layout concerning progression of the disease and various endpoints. Furthermore, TDs along with vessels and nerves exhibit worse prognosis if compared with LNMs alone.

\section{Conclusion}

In conclusion PTDs in pericolonic and mesorectal adipose tissue are invasive adenocarcinoma nodules, developing along large vessels, nerves or straight out from intravascular growth. The presence of tumor deposits was an independent adverse prognostic factor for CRCs patients. The result showed TDs are associated with disease free survival (DFS) in the patient cohort who underwent radical resection separate from lymph node metastasis, regardless of number and size of metastases. Our study was a single- institution retrospective study with a small sample size. To minimize interobserver variation, more exploration and research need to be done to give patients more recognizable diagnosis and resolve a disputes or controversies concerning tumor deposits.

\section{Abbreviations}

TDs: Tumor Deposits; DFS: Disease Free Survival; OS: Overall Survival; GIT: Gastrointestinal Tract; CRC: Colorectal Cancer; PLNC: Positive Lymph Node Count; CEA: Carcinoembryonic Antigen; CA: Carbohydrate Antigen; LNM: Lymph Node
Metastasis; TNM: TNM classification of malignant tumor (Tumor; Nodes; Metastasis); AJCC: American Joint Committee on Cancer; NCCN: National Comphrensive Cancer Network; Cis: Confidence Interval; CT: Computed Tomography; K-M test: Kaplan Meier test.

\section{Acknowledgments}

The work was supported in part by grants of the Shanghai Science and Technology Commission (134119b0600), the Shanghai Municipal Health Bureau (20134194), the National Natural Science Fund of China (81272533), and the Fundamental Research Funds for the central Universities (22120180323).

\section{Competing Interests}

The authors have declared that no competing interest exists.

\section{References}

1. Siegel RL, Miller KD, Jemal A. Cancer statistics, 2018. CA: a cancer journal for clinicians. 2018; 68: 7-30.

2. Torre LA, Bray F, Siegel RL, Ferlay J, Lortet-Tieulent J, Jemal A. Global cancer statistics, 2012. CA: a cancer journal for clinicians. 2015; 65: 87-108.

3. Bibbins-Domingo K, Grossman DC, Curry SJ, Davidson KW, Epling JW, Jr., Garcia FAR, et al. Screening for Colorectal Cancer: US Preventive Services Task Force Recommendation Statement. Jama. 2016; 315: 2564-75.

4. Abdelsattar ZM, Wong SL, Regenbogen SE, Jomaa DM, Hardiman KM, Hendren S. Colorectal cancer outcomes and treatment patterns in patients too young for average-risk screening. Cancer. 2016; 122: 929-34.

5. Edwards BK, Ward E, Kohler BA, Eheman C, Zauber AG, Anderson RN, et al. Annual report to the nation on the status of cancer, 1975-2006, featuring colorectal cancer trends and impact of interventions (risk factors, screening, and treatment) to reduce future rates. Cancer. 2010; 116: 544-73.

6. Chatenoud L, Bertuccio P, Bosetti C, Malvezzi M, Levi F, Negri E, et al. Trends in mortality from major cancers in the Americas: 1980-2010. Ann Oncol. 2014; 25: $1843-53$

7. B. GW, Cuthbert D, R. BHJ. Lymphatic spread in cancer of the rectum. British Journal of Surgery. 1935; 23: 395-413.

8. Sobin L, Wittekind C. TNM Classification of Malignant Tumours. (UICC): Wiley-Blackwell. 2002.

9. Sobin LH, Compton CC. TNM seventh edition: what's new, what's changed: communication from the International Union Against Cancer and the American Joint Committee on Cancer. Cancer. 2010; 116: 5336-9.

10. Washington MK, Berlin J, Branton P, Burgart LJ, Carter DK, Fitzgibbons PL, et al. Protocol for the examination of specimens from patients with primary carcinoma of the colon and rectum. Arch Pathol Lab Med. 2009; 133: 1539-51.

11. Nagtegaal ID, Tot T, Jayne DG, McShane P, Nihlberg A, Marshall HC, et al. Lymph nodes, tumor deposits, and TNM: are we getting better? J Clin Oncol. 2011; 29: 2487-92.

12. Lord AC, D'Souza N, Pucher PH, Moran BJ, Abulafi AM, Wotherspoon A, et al. Significance of extranodal tumour deposits in colorectal cancer: A systematic review and meta-analysis. European journal of cancer (Oxford, England : 1990). 2017; 82: 92-102.

13. Nagayoshi K, Ueki T, Nishioka Y, Manabe T, Mizuuchi Y, Hirahashi M, et al. Tumor deposit is a poor prognostic indicator for patients who have stage II and III colorectal cancer with fewer than 4 lymph node metastases but not for those with 4 or more. Diseases of the colon and rectum. 2014; 57: 467-74.

14. Al Sahaf O, Myers E, Jawad M, Browne TJ, Winter DC, Redmond HP. The prognostic significance of extramural deposits and extracapsular lymph node invasion in colon cancer. Diseases of the colon and rectum. 2011; 54: 982-8.

15. Sobin LH, Fleming ID. TNM Classification of Malignant Tumors, fifth edition (1997). Union Internationale Contre le Cancer and the American Joint Committee on Cancer. Cancer. 1997; 80: 1803-4.

16. Edge SB, Compton CC. The American Joint Committee on Cancer: the 7th edition of the AJCC cancer staging manual and the future of TNM. Ann Surg Oncol. 2010; 17: 1471-4.

17. Ono C, Yoshinaga K, Enomoto M, Sugihara K. Discontinuous rectal cancer spread in the mesorectum and the optimal distal clearance margin in situ. Diseases of the colon and rectum. 2002; 45: 744-9; discussion 2-3.

18. Erin M, M LAA, Xianghua Y, Sheng-Zhong D, Lanjing Z. Prognostic value of tumour deposit and perineural invasion status in colorectal cancer patients: a SEER-based population study. Histopathology. 2016; 69: 230-8. 
19. Ueno H, Mochizuki H, Shirouzu K, Kusumi T, Yamada K, Ikegami M, et al. Multicenter study for optimal categorization of extramural tumor deposits for colorectal cancer staging. Ann Surg. 2012; 255: 739-46.

20. Nagtegaal ID, Knijn N, Hugen N, Marshall HC, Sugihara K, Tot T, et al. Tumor Deposits in Colorectal Cancer: Improving the Value of Modern Staging-A Systematic Review and Meta-Analysis. J Clin Oncol. 2017; 35: 1119-27.

21. Ratto C, Ricci R, Rossi C, Morelli U, Vecchio FM, Doglietto GB. Mesorectal microfoci adversely affect the prognosis of patients with rectal cancer. Diseases of the colon and rectum. 2002; 45: 733-42; discussion 42-3.

22. Tong LL, Gao P, Wang ZN, Song YX, Xu YY, Sun Z, et al. Is the seventh edition of the UICC/AJCC TNM staging system reasonable for patients with tumor deposits in colorectal cancer? Ann Surg. 2012; 255: 208-13.

23. Song YX, Gao P, Wang ZN, Liang JW, Sun Z, Wang MX, et al. Can the tumor deposits be counted as metastatic lymph nodes in the UICC TNM staging system for colorectal cancer? PLoS One. 2012; 7: e34087.

24. Lin Q, Wei Y, Ren L, Zhong Y, Qin C, Zheng P, et al. Tumor deposit is a poor prognostic indicator in patients who underwent simultaneous resection for synchronous colorectal liver metastases. Onco Targets Ther. 2015; 8: 233-40.

25. Goldstein NS, Turner JR. Pericolonic tumor deposits in patients with T3N+MO colon adenocarcinomas: markers of reduced disease free survival and intra-abdominal metastases and their implications for TNM classification. Cancer. 2000; 88: 2228-38.

26. Puppa G, Maisonneuve P, Sonzogni A, Masullo M, Capelli P, Chilosi M, et al. Pathological assessment of pericolonic tumor deposits in advanced colonic carcinoma: relevance to prognosis and tumor staging. Modern pathology : an official journal of the United States and Canadian Academy of Pathology, Inc. 2007; 20: 843-55.

27. Wunsch K, Muller J, Jahnig H, Herrmann RA, Arnholdt HM, Markl B. Shape is not associated with the origin of pericolonic tumor deposits. Am J Clin Pathol. 2010; 133: 388-94. 